\title{
Postscript: Launching an International Network of Home-based Workers During the covid- 19 Crisis
}

\author{
Chris Bonner, Jane Barrett, Janhavi Dave
}

In the chapter "Home-based Workers: Organizing from Local to Global" plans for the launch a global network of home-based workers' organizations - HomeNet International - were discussed. Whilst a representative working group was finalizing such plans, COVID-19 struck and disrupted them. And importantly, it decimated the livelihoods of home-based workers. However, home-based workers' organizations were determined to forge ahead. On February 24, 2021, HomeNet International became a reality. 8 o home-based workers official delegates from 36 new affiliates in 20 countries came together in a virtual congress to launch their global network. They were joined by more than 400 observers including 200 home-based workers from affiliates and emerging affiliates, and more than 200 allies and supporters.

HomeNet International's constituency consists of working poor home-based workers, a majority being women. These home-based workers' incomes are generally low and insecure, whether as own account workers or sub-contracted piece rate workers, and they have little access to legal and social protections. This means that when disaster strikes they have little to fall back on.

And so this was, and still is, with the coviD-19 disaster, as work and income dried up, leaving many with little or no means to support themselves and their families. In a twelve-city study by Women in Informal Employment (WIEGO) on the effects of the pandemic on workers in the informal economy, including home-based workers, one of the most shocking findings was the level of hunger reported. ${ }^{1}$ HomeNet South Asia, in a similar study in seven countries

1 WIEgo. "The COVID-19 Crisis and the Informal Economy: Global Summary Report", June 2021. Accessible at www.wiego.org, last accessed 28 May 2021.

(C) CHRIS BONNER, JANE BARRETT, JANHAVI DAVE, 2022 | DOI:10.1163/9789004499614_024

This is an open access chapter distributed under the terms of the CC BY-NC-ND 4.o license. 


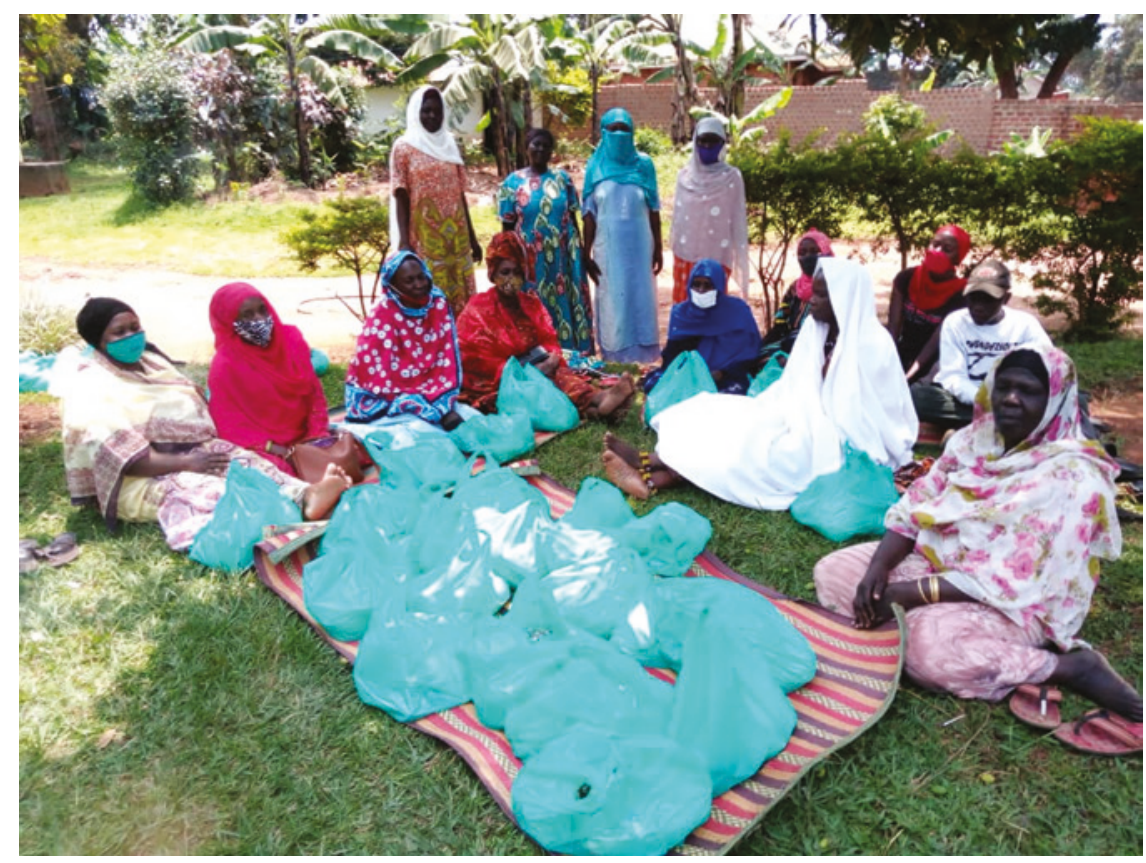

FIGURE 21.1 A group of Nubian home-based workers near Entebbe, Uganda receiving food relief in October 2020 organized by HomeNet International during the pandemic

of South Asia with 394 home-based worker respondents, found that seventy per cent had no income during the lockdown, used up all their savings and went into debt. ${ }^{2}$ Both these studies were carried out in 2020, but in 2021 as new waves of the pandemic hit, the slow recovery from this stalled. On International Workers' Day 2021, in a global webinar organized by HomeNet International, home-based workers reported on their current situation. They spoke of "lost work", "no orders", "grief and depression", "lack of food", "family eats once a day", " products piling up", "no money to go to hospital", "on-line education difficult to afford for children", "government provides no support for HBWs", amongst others. For many, their main support is from their organizations, for both physical and mental wellbeing.

On the more positive side home-based workers in established and stronger organizations, were better able to sustain themselves, as their organizations were able to change supply chains from international to domestic, and focus

2 HomeNet South Asia, "Impact of Covid-19 on Women Home-based Workers in South Asia", December, 2020. Accessible at: www.hnsa.org.in, last accessed 26 May 2021. 
on different products. Janhavi Dave, HomeNet International Coordinator, further noted,

[...] the membership of many grassroots organizations increased during the pandemic. The reason for that was that they were the only ones who were able to create access to government assistance programmes or food, and coming together and having a joint voice for demanding things like social protection. ${ }^{3}$

It is in this context that HomeNet International was launched, and has taken its first steps towards a strong global voice for home-based workers.

During the early months of the pandemic home-based workers' organizations were busy with relief and recovery activities. Mobilizing for the formation of HomeNet International was not possible, and the nascent global network turned to supporting humanitarian relief efforts, holding virtual events to build unity and solidarity across the diverse regions, and promoting the demands of home-based workers for inclusion in government assistance programmes, compensation from brands, and social protection measures.

However, as noted above, the benefits of organizing were becoming clearer, including the need for, and benefits of, global solidarity, and a global voice. Once the decision was taken to launch HomeNet International virtually, the Interim International Working Group (IIWG), leading the process towards congress, began to mobilize and formally recruit affiliates.

Organizing the congress was practically and politically challenging. Although the IIWG, assisted by WIEGO, was gaining experience in organizing on-line meetings and workshops, organizing a congress was more complex. There were practical issues to overcome. A union congress would normally take place over two to three full days, but in this case affiliates were separated by time and space. The time differences stretched over fourteen hours. So whilst delegates in Nicaragua logged on at 6.30 in the morning for a two and a half hour session on two consecutive days, those from the Philippines joined the congress at 20.30 in the evening when they would normally be preparing for bed. This

3 WIEGO, "The Creation of HomeNet International", May 2021, available at www.wiego.org, last accessed 26 May 2021. 
limited the time available for decision-making and direct participation. Apart from the obvious difficulties facing home-based worker participants- poor internet connections, data and device limitations, electricity outages and so forth- interpretation had to be provided in seventeen languages.

These practical limitations created political challenges. How could a sense of solidarity and camaraderie across diverse organizations infuse the congress without formal and informal face-to-face interactions? How could one adopt a founding constitution without time for a full debate, or the opportunity to hold caucus meetings and negotiations to settle differences? How could fair elections be organized where not all delegates had their own devices and where poll facilities on the internet platform were all in English?

Mobilization, planning and preparation were key to mitigating these challenges, and the IIWG, together with WIEGO, worked hard to ensure practical difficulties were minimized. Politically, it was important before the congress to include activities that would help build a common identity and solidarity. With such diversity amongst the affiliates in size (from small groups of 50 to over 300,00o members), political, economic and cultural context, and organizational history, this was just as important as taking organizational decisions. To this end, songs, poems, messages and reports from the different regions in many languages formed an important part of the proceedings- all prepared in advance by the affiliates and presented through video and powerpoint. Sharing the struggle history of the home-based workers' movement was another important element in solidarity building, with long-time supporters of the movement providing insights and lessons learnt. Ela Bhatt, now in her late eighties and recognised as the founder of the home-based workers' movement, recounted some of the early history, including the struggle for global recognition and how the ILO Convention on Home-Work ( $\mathrm{C}_{177}$ ) was adopted. And, participants were surprised to learn that in 1994, prior to the ILO discussions, an earlier version of HomeNet International was formed, but that it failed to transform into a democratic global network of membership-based organizations.

Ensuring that key decisions were made to allow HomeNet International to move forward meant a tight agenda, firm chairing and good preparation. The constitution presented at congress was the product of a two-year participatory process. A spirit of cooperation across the regions meant that final changes proposed in regional preparatory meetings, also held virtually, were settled prior to congress. Similarly, affiliates agreed to appoint a transitional leadership committee, rather than to try and hold elections virtually. In addition, congress approved all new affiliates, appointed an International Coordinator, approved affiliation fees and laid out a broad agenda for HomeNet International over the next two years. 


\section{Future Prospects}

An immediate internal priority for HomeNet International is to continue solidarity building across diverse affiliates and regions. This is the foundation on which future development rests. The new leadership committee, at the time of writing (May 2021), has met three times and begun a programme of activities focusing on sharing experiences on important common issues such as the COVID-19 situation, recovery demands, social protection, the solidarity economy, and livelihood strategies. It is also focused on developing governance and operational structures, policies and systems that meet the needs of affiliates, and, as a democratic worker organization, ensures membership is informed and involved.

With the on-going pandemic, the future of working poor home-based workers, and the resilience of their organizations remain uncertain, but the experience to date of HomeNet International and its affiliates provides for cautious optimism. Raising the visibility of home-based workers so that they gain recognition as workers and have a global voice is an important function of HomeNet International. The focus on the growing number of home-based workers - especially newer forms of non industrial home based workers such as teleworkers and digital platform workers- outlined in a recent ILO Report, ${ }^{4}$ and fuelled further by the pandemic, could be the start of more widespread recognition of the value of all home-based work and the need for worker rights and protection. Concentrating on what unites all home-based workers, industrial and non-industrial, rather than on divisions of class and culture could provide the basis for issue-based solidarity and tactical alliances in the struggle of all home-based workers worldwide for decent work. Drawing on the lessons of history as recorded in this unique book, will be critical to this struggle for decent work.

4 ILO, "Working from Home. From Invisibility to Decent Work", Geneva, 2021. 